\title{
Cancer treatment through hormone therapy and its relationship with Xerostomia and Hyposalivation
}

Glaucia de Medeiros ( $\square$ gaufaraco@gmail.com )

Universidade do Sul de Santa Catarina - Campus Tubarao https://orcid.org/0000-0003-1403-2962

Jheiniffer Fernandes

Universidade do Sul de Santa Catarina - Campus Tubarao

Daniela Pompeo

Universidade do Sul de Santa Catarina - Campus Tubarao

Jefferson Ricardo Pereira

Universidade do Sul de Santa Catarina - Campus Tubarao

Research article

Keywords: Breast Cancer; Prostate Cancer Xerostomia; Hyposalivation; Tamoxifen.

Posted Date: March 13th, 2020

DOl: https://doi.org/10.21203/rs.3.rs-17125/v1

License: (9) This work is licensed under a Creative Commons Attribution 4.0 International License.

Read Full License 


\section{Abstract}

Background: the emergence of new drugs for cancer treatment has reflected on increasing patient survival. However, these drugs bring side effects, such as dry mouth sensation and hyposalivation. This study aimed to evaluating the relationship between patients with cancer and xerostomia and hyposalivation. Method : cross-sectional study with 114 patients diagnosed with cancer treated with anastrozole and / or bicalutamide. Age, type of neoplasia, gender, xerostomia, and type of medicine were obtained through questionnaire. Resting and stimulated salivary flow were collected by the researcher. After collection, using a $10 \mathrm{~mL}$ disposable syringe, salivary flow was quantified in millimeters and divided into 6 (collection period). A Descriptive statistical analysis, Chi-square test and T-test were carried out through Statistical Package for Social Science ${ }^{\circledR}$ (SSPS) version 21, considering $p<0.05$. Results : results showed that 67 (55.8\%) patients who use hormone therapy presented hyposalivation and $73(64.0 \%)$ patients presented xerostomia. Conclusion : According to the results from this study, there is statistically significant association between stimulated hyposalivation and hormone therapy usage $(p=0.015)$. Statistically significant association was also observed among hyposalivation and xerostomia and hormone therapy usage $(p=0.049$ and $p=0.001)$.

\section{Background}

Cancer is the second most common cause of death worldwide, regardless the country development level. While in developed countries cancers with higher incidence and prevalence are in lung, breast and prostate, countries in development have high incidence of cancer related with infection in cervix, stomach, esophagus and liver [1, 2].

Cancer treatment should start in the moment in which the patient has his/her diagnosis confirmed, and it consists in a series of multi professional interventions that includes surgery, radiotherapy, chemotherapy, hormone therapy and target therapy. The choose for one or another treatment depends on different factors, such as the original place and invasion degree. In numerous cases, a combination of different modalities is recommended. For cases treated with hormone therapy, the main drugs used to treat breast and prostate cancers are: Tamoxifen when there are receptors for estrogen in tumor mass, inhibiting its production; Anastrozole, which is an aromatase inhibitor also with action on estrogen in postmenopausal women; and Bicalutamide, which acts inhibiting androgen hormones [2, 3, 4]. Among other factors, the choice for one or another treatment is determined by the tumor type and staging. While the use of Tamoxifen is recommended for pre-menopausal women, postmenopausal women might use both Tamoxifen and Anastrozole [5]. They are used orally and may have their action influenced when used concomitantly with other drugs, as well as may provoke side effects in the mouth.

Some studies have demonstrated the estrogen as important for maintenance of bone and soft tissues in the oral cavity. Then, drugs which affect its production preclude or may difficult estrogen link with its receptors. One example is the Anastrozole, which may affect the bone and soft tissues in the mouth, increasing the risk for periodontal disease, taste change, salivary flow decreased and xerostomia $[5,6]$. 
Xerostomia is characterized by dry mouth sensation, and it may be on primary or secondary types. Primary xerostomia is caused by decreased resting or stimulated salivary production, and the second type is caused by dry mouth with no changes in salivary flow. Among xerostomia etiology, there are systemic factors, like diabetes, rheumatoid arthritis, Sjögren's syndrome, hepatitis and HIV; or local factors, like anticholinergic, antidepressant, antineoplastic, antipsychotic and antihypertensive drugs. Radiation on head and neck region, smoking, alcoholism, as well as excessive consumption of coffee are also among local factors which may lead to xerostomia [7.8.9.10].

Patients with xerostomia might have difficult to feed themselves and/or talk, further present burning, halitosis and change in taste. Lip dryness, oral thrush and caries may also occur, even in patients with good oral hygiene. Early identification of etiological factor and consequently determination of diagnosis, even primary or secondary types allows introducing a more effective treatment plan in order to reach control and comfort, especially for women over 60 years old $[7.9,10]$.

Literature is scarce regarding the relation between xerostomia and/or hyposalivation and hormone therapy usage. Regarding the Bicalutamide use by patients with prostate cancer, there is no study. Studies regarding the Anastrozole usage are not specific for this condition. They evaluate changes in oral cavity not as a whole and did not determine in which treatment stage is more frequently found $[5,8,11]$.

In estrogen receptors specific case, studies have shown this hormone in the buccal mucosa and in the salivary glandules. An antagonist action to this hormone may be responsible by dry mouth sensation [5, 12, 13]. Preliminary results of a pilot study performed by Taichman et al. [5] did not show perception difference between dry mouth and decreased salivary flow of patients using aromatase and patients without the drug. However, longitudinal study performed by the same authors [13] and published in 2016 alerts to the decreased salivary flow in long term caused by using aromatase inhibitors, and highlights that more studies must be performed, because these patients need special care regarding their oral health.

Then, the hypothesis for this research is the Anastrozole and Bicalutamide used for breast and prostate cancers, respectively, cause changes on salivary flow and xerostomia. This research had as aim at evaluating the relation between xerostomia and hyposalivation with hormone therapy used in patients under oncologic treatment, through salivary flow dosage.

\section{Method}

This research was a cross-sectional observational epidemiological study that evaluated 114 patients with age over 18 years old under hormone therapy with Anastrozole or Bicalutamide for breast and prostate cancer treatment respectively, in the Oncology Ambulatory Unit in Nossa Senhora da Conceição Hospital (Tubarão, Santa Catarina, Brazil). Data collection period was from July to October 2016. The procedure of random sampling and convenience was adopted. The Project was approved by the Research and Ethics Committee of the University of Southern Santa Catarina under the number CAAE: 57324716.2.0000.5369, advice number 1.619.905. 
Sociodemographic data such as age, gender, cancer type, therapy and other medicine used, smoking and coffee consumption were obtained by self-completed questionnaire. Patients also answered questions on dry mouth sensation, lip dryness and salivary amount they believed to have. Salivary flow evaluation was performed under methodology proposed by Sreebny and Valdini [14]. There were two moments of saliva collection, one at rest and another stimulated. For the rest salivary collection, the patient was instructed to sit down in a comfortable way and expel the saliva in a plastic recipient for 6 minutes continuously. For stimulated saliva collection, a piece of latex was chewed, with $3 \mathrm{~mm}$ thickness and $1 \mathrm{~cm}$ length, tied by a dental floss to avoid deglutition. Then, the saliva produced was deposited in another plastic recipient also for 6 minutes. After a rest period to decrease the saliva foam interference, salivary flow was quantified in millimeters using a $10 \mathrm{~mL}$ disposable syringe and dividing into 6 to obtain the $\mathrm{mL}$ amount per minute, considering the hyposalivation values $\leq 0.1 \mathrm{~mL} / \mathrm{min}$ for rest and $\leq 0.7 \mathrm{~mL} / \mathrm{min}$ when stimulated. The values were registered in their respective questionnaires.

Data collected were inserted in the Statistical Package for Social Science® (SSPS) version 21.0 for descriptive analysis of data normality and statistically inference to determine the average, standard deviation and mean standard error. Chi-square test was used to verify association among variables and tstudent test was used to determine the difference of average among the groups. The results were considered statistically significant for $<0.05$.

\section{Results}

From the 114 patients who constituted the sample, $16(14 \%)$ were male with prostate cancer diagnosis, and the drug used was bicalutamide; and 98 (86\%) were female with breast cancer diagnosis under treatment with anastrozole. Age average was $64.88(\mathrm{EP}+/-0.87)$ years, with the minimum age 43 years and maximum age 86 years old. The mode was 67 years old.

Regarding the habits, only 9 (7.9\%) were smokers, while 31 (27. $2 \%)$ were ex-smokers.

The Test - $X 2$ did not show statistically significant result among smoke, rest and stimulated hyposalivation and xerostomia, as provided by table 1 .

Further the antineoplastic drugs, 92 patients (80.7\%) were using another kind of medicine, especially for cardiovascular disease or mental disorders. The use of these drugs was prescribed before the cancer treatment for $70(76.1 \%)$ patients. Table 2 shows the distribution of dry mouth sensation (xerostomia) reported by patients according to the time and use of drugs.

There was no statistically significant result among the use of other drugs and rest or stimulated hyposalivation as shown by table 3 .

The average of salivary flow at rest was $0.14 \mathrm{~mL} / \mathrm{min}(E P)$, while the average of stimulated salivary flow was $0.48 \mathrm{~mL} / \mathrm{min}$ (EP Figure 1 and 2 show the volume distribution of rest and stimulated salivary flow. 
The average volume of rest salivary flow for patients who was using Anastrozole was $0.13 \mathrm{~mL} / \mathrm{min}$ (EP, while the average volume of stimulated salivary flow was $0.51 \mathrm{~mL} / \mathrm{min}(E P)$. For patients who was using Bicalutamide, the average volume of rest salivary flow was $0.24 \mathrm{~mL} / \mathrm{min}$ (EP, while the average volume of stimulated salivary flow was $0.97 \mathrm{ml} / \mathrm{min}$ (EP). The volume of stimulated salivary flow presented statistically significant result among the different groups $p=0.0001$ (IC: $-0.70 /-0.205$ ).

The association among the hormone therapy used and the presence of rest and stimulated hyposalivation is demonstrated in the table 4 , and it showed statistically significant result for stimulated hyposalivation.

When considered the association among the hormone therapy and hyposalivation, regardless the stimulation of salivary flow and xerostomia, the Test $-X^{2}$ presented statistically significant result $p=$ $0.049 ; p=0.001$, respectively, as shown in the table 5 .

\section{Discussion}

Considering the results found in this study, the hypothesis for research that there is change on the salivary flow and xerostomia in patients in cancer treatment may be accepted.

Several studies $[15,16,17]$ indicate that smoking increases the activity of salivary glands, but in short term. The more prolonged the habit and higher the cigarettes consumption, the higher the chances for changes on salivary flow and xerostomia. The same authors also highlight that the studies approaching this relationship are scarce. Time of smoking was not verified in this study, but the results corroborate those found in literature $[15,16,17]$, what allows us suggest that further time of smoking, the actions of toxins from nicotine lead to damages in salivary glandules, reflecting on salivary flow.

High percentage of patients who use other drugs further those for cancer treatment reflects on the world panorama that makes evident the high incidence and prevalence of nontransferable chronic diseases, such as cardiovascular ones and mental disorders, depression and anxiety among them $[1,8,18]$. Johanson and colleagues [19] point out the potential of these drugs provoke xerostomia and of leading to salivary, results also made evident through this research. Despite salivary flow tests were performed only once already with hormone therapy in use, it is not possible assert that the salivary flow change and xerostomia already were present previously the antineoplastic treatment or whether they were potentiated with the association of more this drug.

The average of rest salivary flow found in this study was higher than the value found by Niklander [17] and Villa [20], what makes evident there is no functional changes on salivary glandules. When the average of stimulated salivary flow was observed, the results are according to those obtained by Falcão [21] and Lago [22]. This situation allows us to infer that drugs used on hormone therapy act on salivary glandules, decreasing their production when they suffer stimulation. 
Aromatase inhibitors, such as Anastrozole, have been the hormone therapy selected for breast cancer treatment in postmenopausal women, because they act inhibiting the estrogen production, decreasing the cancer growth and avoiding relapse. Among the side effects are salivary flow decreased, regardless stimulation or not [5], and this result was also made evident in this research. Further the postmenopausal or pre-menopause condition was not verified in patients, the mean age of patients leads to believe that most of them were postmenopausal. Studies such as by Foschin and colleagues published in 2017 [23] makes evident the presence of estrogen receptors in salivary glandules tumors, showing this hormone in the mucosa of glandules. Decreasing of estrogen production due to the hormone therapy might lead to decrease salivary production, resulting in hyposalivation.

A study made evident that androgenic hormone decreases in women at menopause age and this condition predispose the Sjögren's syndrome [24]. This research is the first study which evaluates association among hormone therapy with antiandrogenic action, hyposalivation and xerostomia, despite the statistically significant result demonstrated for hyposalivation when there is stimulated salivary flow, xerostomia and hyposalivation. Decreased or absence of androgenic hormone in these patients by hormone therapy action might be responsible by salivary flow changes found in them. However, more studies are suggested for better understand this condition.

Dry mouth sensation in this study was determined by the patient's self-perception. It is known that the symptom is different from one person to another, and the absence of a pattern for answers may under or overestimated the results found. This same limitation was observed in other studies $[26,27,28]$ that demonstrate relation among xerostomia and numerous oncologic diseases, strong relation of radiotherapy in head and neck region and women over 60 years old [8, 9].

Even with limitations, the findings from this research demonstrate presence of hyposalivation of xerostomia in patients under hormone therapy and such condition affects or aggravates the quality of life. It is known that hormone therapy usage is prolonged, achieving ten years in treatment. Identifying whether this condition comes from the treatment, in what post-treatment it starts, whether there is aggravation or not during this time and whether it returns after finishing may allow early diagnosis with better or faster approach. Thereunto, new studies are suggested, cohort type for most reliable monitoring such condition.

\section{Conclusion}

Results from this study allow to conclude that:

- Anastrozole and Bicalutamide presented statistically significant results for the average volume of stimulated salivary flow $\mathrm{p}=0.0001$ (IC: $-0.70 /-0.205$ ).

- Anastrozole and Bicalutamide cause statistically significant decrease of stimulated hyposalivation $(p=p=0.049)$. 
- Xerostomia is a frequent complaint among patients who uses Anastrozole and Bicalutamide, and they presented statistically significant result $(p=0.001)$.

\section{Declarations}

Ethics approval and consent to participate: The Project was approved by the Research and Ethics Committee of the University of Southern Santa Catarina under the number CAAE: 57324716.2.0000.5369, advice number 1.619.905. Each participant provided written informed consent.

Consent for publication: Not Applicable

Availability of data and materials: The datasets used and/or analysed during the current study are available from the corresponding author on reasonable request.

Competing interests: The authors declare that they have no competing interests.

Funding: Not Applicable

Authors' contributions: GHFM And JF. conceived the study, participated in its design and coordinated data collection.. GHFM was involved in statistical analysis and JF, DDP, JRP in data interpretation. GHFM, DDP, JRP helped to draft the manuscript. All authors read and approved the final manuscript.

Acknowledgements: Not Applicable

\section{References}

1. World Health Organization. Breast cancer. http://www.who.int/cancer/prevention/diagnosisscreening/breast-cancer/en/. (Accessed May 05, 2018).

2. Ferlay J, Soerjomataram I, Dikshit R, Eser S, Mathers C, Rebelo, M.; Parkin, DM, Formanm D, Bray F. Cancer incidence and mortality worldwide: sources, methods and major patterns in GLOBOCAN 2012. Int.J. Cancer., 2015, 136(5), E359-386.

3. Protocolos clínicos e diretrizes terapêuticas em oncologia. Ministério da Saúde, 2014.

4. Agência Nacional de Saúde Suplementar. Parecer técnico n27.

http://www.ans.gov.br/images/stories/parecer_tecnico/uploads/parecer_tecnico/_PARECER_272018_MEDICAMENTOS\%20ANTINEOPLSICOS\%200RAIS_VERSO\%20FINAL_27122017.pdf. (Acessed May 05, 2018).

5. Taichman LS, Inglehart MR, Giannobile WV, Braun T, Kolenic G, Poznak VC. Periodontal health in women with early-stage postmenoaousal breast cancer newly on aromatase inhibitors: A pilot Study. J. Peridontol., 2015, 86(7), 905-916.

6. Hanchanale S, Adkinson L, Daniel S, Fleming M, Oxberry SG. Systematic literature review: xerostomia in advanced cancer patients. Support. Care Cancer., 2015, 23, 881-888. 
7. Millsop JW, Wang EA; Fazel, N. Etiology, evaluation and management of xerostomia. Clin. Dermatol., 2017, 35(5), 468-476.

8. Barbe AG. Medication -induced xerostomia and hyposalivation in the elderly: culprits, complications, and management. Drugs \& Aging., 2018, 35(10), 877-885.

9. Astrom AN, Lie SA, Ekbacj G, Gulcan F, Ordell S. Self- reported dry mouth among ageing people: a longitudinal, cross-national study. Eur. J. Oral. Sci, 2019, 127(2), 130-138.

10. Singh M, Tonk RS. Management of salivary hypofunction. Pharm. Anal. Acta., 2015, 6(2), 331- 332.

11. Sözeri E, Kutlutürkan S. Taste Alteration in Patients Receiving Chemotherapy. J. Breast. Heralth, $2015,11(2), 81-87$.

12. Liu S, Niu K, Da Y, Liu Y, Zhang J, Wang W, et al Effects of standardized isopropanolic black cohosh and estrogen on salivary function in ovariectomized rats. Biomed. Pharmother., 2018, 97, 14381444.

13. Taichman LS, Van Poznak C.H, Inglehart MR. Self-reported oral health and quality of life of postmenopausal breast cancer survivors on aromatase inhibitors and women without cancer diagnoses: a longitudinal analysis. Support. Care. Cancer., 2016, 24(11), 4815-4824.

14. Sreebny LM, Valdini A, Yu A. Xerostomia. Part II: Relationship to nonoral symptoms drugs and diseases. Oral. Surg. Oral. Med. Oral. Pathol., 1989, 68(4), 419-427.

15. Rad M, Kakoie S, Brojeni FN, Pourdamghan N. Effect of logn -term smoking on whole- mouth salivary flow rate and oral health. J. Dent. Res. Dent. Clin. Dent. Prospects., 2010, 4(4), 110- 114.

16. Dyasannor S, Saddu SC. Association of Xerostomia and Assessment of Salivary Flow Using Modified Schirmer Test among Smokers and Healthy Individuals: A Preliminutesary Study. J. Clin. Diagn. Res., 2014, 8(1), 211- 213.

17. Niklander S, Veas, L, Barrera C, Fuentes F, Chiappini G, Marshall M. Risk factors, hyposalivation and impact of xerostomia on oral health-related quality of life. Braz. Oral. Res., 2017, 31, e14.

18. Rech CA, Medeiros AW. Xerostomia associada ao uso de medicamentos em idosos. J. Oral. Invest.; 2016, 5(1), 13-18.

19. Johanson CN, Osterberg T, Lernfelt B, Ekstrom J, Birkherd D. Salivary secretion and drug treatment in four 70-year-old Swedish cohorts during a period of 30 years. Gerodontology, 2015, 32(3), 202-2010.

20. Villa A, Wolff A, Aframian D, Vissink A, Ekstrom J, Proctor G, et al. World Workshop on Oral Medicine Vl: a systematic review of medication-induced salivary gland dysfunction: prevalence, diagnosis, and treatment. Clin. Oral. Investig., 2015, 19(7), 1563-1680.

21. Falcão DP, Mota LM, Pires AL, Bezerra AC. Sialometry: aspects of clinical interest. Rev. Bras. Reumatol., 2013, 53(6), 525-531.

22. Lago ML, Oliveira AE, Lopes FF, Ferreira EB, Rodrigues VP, Brito LM. The influence of hormone replacement therapy on the salivary flow of post-menopausal women. Gynecol. Endocrinol., 2015, 31(2), 109- 112. 
23. Foschini MP; Morandi L; Asioli S, Giove G, Corradini AG, Eusebi V. The morphological spectrum of salivary gland type tumours of the breast. 2017 Feb;49(2):215-227. doi:

10.1016/j.pathol.2016.10.011. Epub 2016 Dec 30.V2.

24. Bayetto K, Logan RM. Sjögren's syndrome: a review of aetiology, pathogenesis, diagnosis and management. Australian Dental Journal 2010; 55:(1 Suppl): 39-4

25. Mercadante S, Alelli F, Adile C, Ferreira P, Valle A, Fusco F, el al. Prevalence of oral mucositis, dry mouth, and dysphagia in advanced cancer patients. Support. Care Cancer, 2015, 23(11), 3249-3255.

26. Baharvand M, Khodadoustan A, Mohammadi M, Mortazavi H, Movahhedlan A. Xerostomia due to systemic disease: A review of 20 conditions and mechanisms. Ann. Med. Health. Sci. Res., 2014, 4(4): 503-510.

27. Wilberg P, Hjermstad MJ, Ottesen S, Herlofson BB. Oral health is an important issue in end-of-life cancer care. Support. Care Cancer., 2012, 20(12), 3115-3122.

\section{Tables}

Table 1: Association among smoke, rest and stimulated hyposalivation and xerostomia

\begin{tabular}{|c|c|c|c|c|c|c|}
\hline \multirow[t]{5}{*}{ Smoke } & \multicolumn{4}{|c|}{ Hyposalivation } & \multirow{2}{*}{\multicolumn{2}{|c|}{$\begin{array}{l}\text { Xerostomia } \\
\qquad \mathrm{P}=0.954\end{array}$}} \\
\hline & \multicolumn{2}{|c|}{ Rest } & \multicolumn{2}{|c|}{ Stimulated } & & \\
\hline & \multicolumn{2}{|c|}{$\mathrm{P}=0.113$} & \multicolumn{2}{|c|}{$\mathrm{P}=0.958$} & \multicolumn{2}{|c|}{ IC: (0.950-0.958) } \\
\hline & \multicolumn{2}{|c|}{ IC: $(0.106-0.199)$} & \multicolumn{2}{|c|}{ IC: (0.954- 0.962) } & \multirow[b]{2}{*}{ Yes } & \multirow[b]{2}{*}{ No } \\
\hline & Present & Absent & Present & Absent & & \\
\hline$\leq 1$ year & 0 & $5(100)$ & 0 & $5(100)$ & $4(80)$ & $1(20)$ \\
\hline$>1$ year and $\leq 10$ years & $5(62.5)$ & $6(60)$ & $1(12.5)$ & 7 (87.5) & $5(62.5)$ & $3(37.5)$ \\
\hline$>10$ years and $\leq 20$ years & $4(40)$ & 1 (12.5) & $21(10)$ & $9(90)$ & $6(60)$ & $4(40)$ \\
\hline$>20$ years & $5(62.5)$ & $3(37.5)$ & $2(25)$ & $6(75)$ & $6(75)$ & $2(25)$ \\
\hline Smoker & $3(33.3)$ & $6(66.7)$ & $1(11.1)$ & $8(89.9)$ & $5(55.6)$ & $4(44.4)$ \\
\hline No smoker & $44(59.5)$ & $30(40.5)$ & $12(16.2)$ & $62(83.3)$ & $47(63.5)$ & $27(36.5)$ \\
\hline Total & $63(53.3)$ & $51(44.7)$ & $17(14.9)$ & $97(85.1)$ & $73(64)$ & $41(36)$ \\
\hline
\end{tabular}

Table 2: distribution of dry mouth sensation according to the use of other drugs 


\begin{tabular}{lcc}
\multicolumn{1}{c}{ Other drugs usage } & \multicolumn{2}{c}{ Dry mouth sensation } \\
& Population n= 114 n (\%) \\
\cline { 2 - 3 } & Present & Absent \\
\hline No use of drugs & - & 22 \\
\hline Before starting the use of the drugs & $21(3)$ & $49(70)$ \\
\hline After starting the use of the drugs & - & 22 \\
\hline Total & $21(18)$ & $93(81.6)$
\end{tabular}

Table 3: Association among rest and stimulated hyposalivation and the use of other drugs ( .

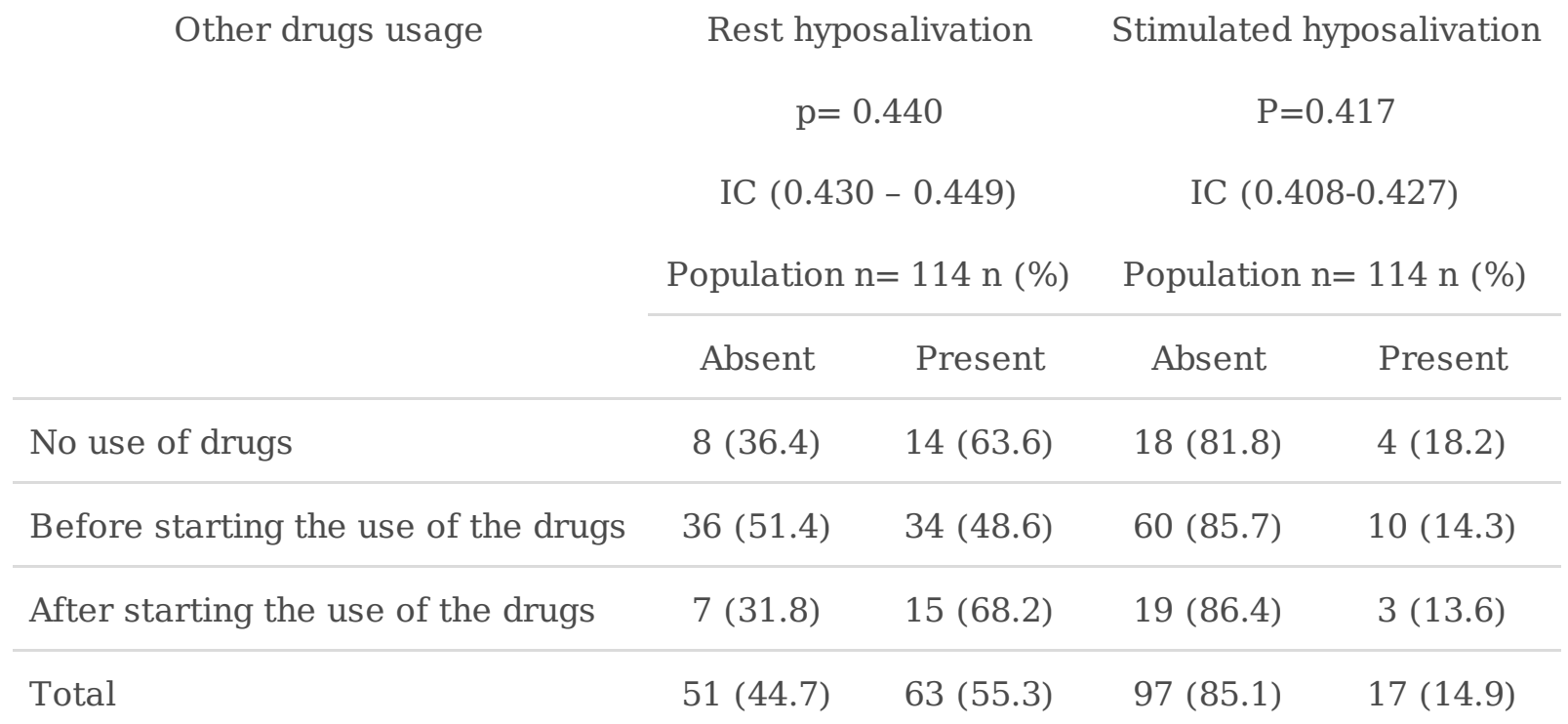

Table 4: Association among hormone therapy and rest and stimulated hyposalivation 
Hormone therapy Rest hyposalivation Stimulated hyposalivation

$$
\mathrm{p}=0.65 \quad \mathrm{P}=0.015
$$

\begin{tabular}{lcccc} 
& \multicolumn{2}{c}{ Population $\mathrm{n}=114 \mathrm{n}(\%)$} & Population $\mathrm{n}=114 \mathrm{n}(\%)$ \\
\cline { 2 - 5 } & Absent & Present & Absent & Present \\
\hline Anastrozole & $43(43.9)$ & $55(56.1)$ & $87(88.8)$ & $11(11.2)$ \\
\hline Bicalutamide & $8(50)$ & $8(50)$ & $10(62.5)$ & $6(37.5)$ \\
\hline Total & $51(44.7)$ & $63(55.3)$ & $97(51.1)$ & $17(14.9)$
\end{tabular}

Table 5: Association between hyposalivation and hormone therapy

\begin{tabular}{lcccc} 
Hormone therapy & \multicolumn{2}{c}{ Hyposalivation } & \multicolumn{2}{c}{ Xerostomia } \\
& \multicolumn{2}{c}{$\mathrm{p}=0.049$} & $\mathrm{p}=0.001$ \\
& \multicolumn{2}{c}{ Population $\mathrm{n}=114 \mathrm{n}(\%)$} & Population $\mathrm{n}=114 \mathrm{n}(\%)$ \\
\cline { 2 - 5 } & Absent & Present & Absent & Present \\
\hline Anastrozole & $44(49.9)$ & $54(55.1)$ & $29(29.6)$ & $69(70.4)$ \\
\hline Bicalutamide & $3(18.8)$ & $13(81.3)$ & $12(75.0)$ & $4(25.0)$ \\
\hline Total & $47(41.2)$ & $67(55.8)$ & $41(36.0)$ & $73(64.0)$
\end{tabular}

Figures 


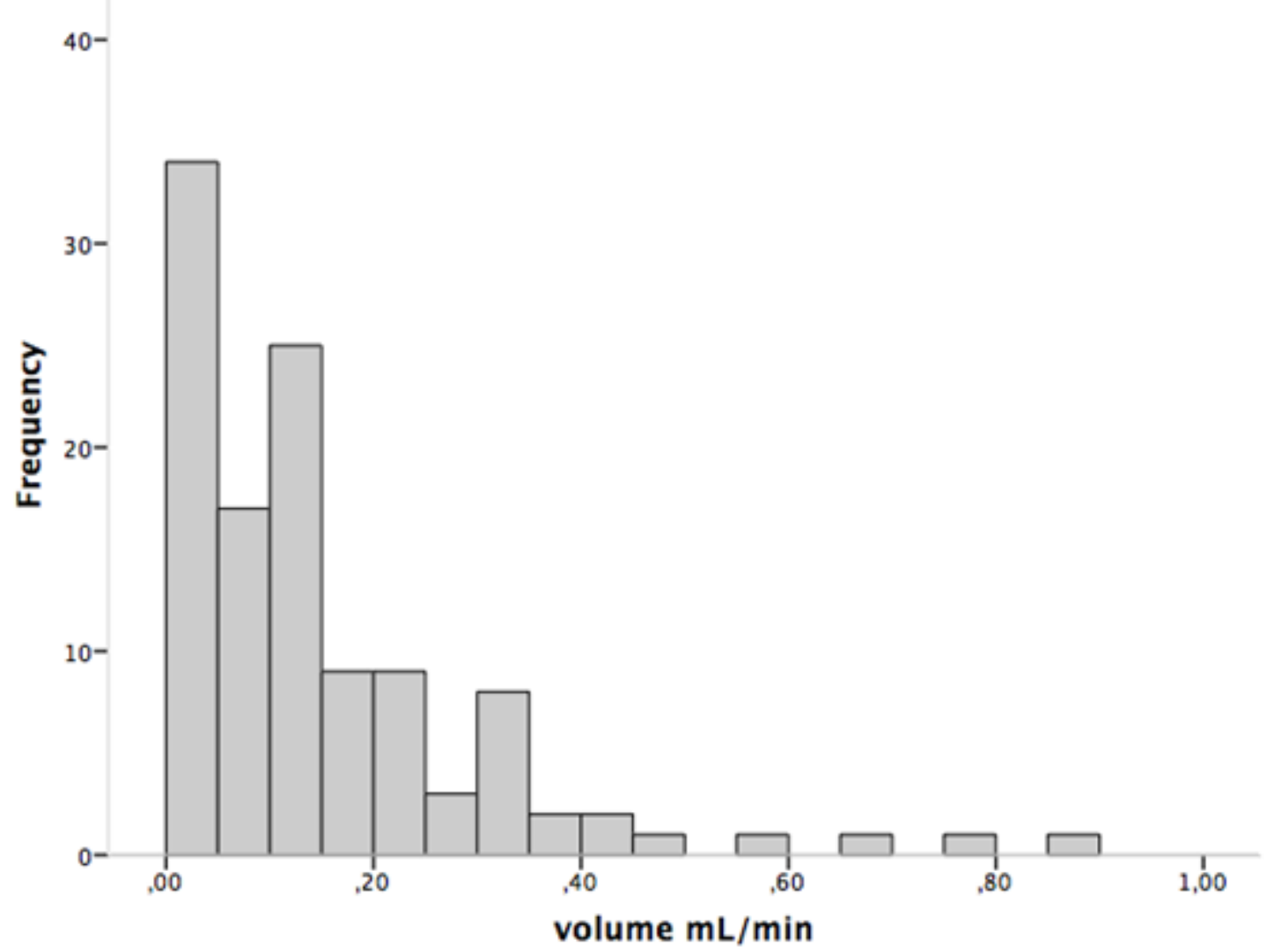

Figure 1

Distribution of rest salivary flow volume 


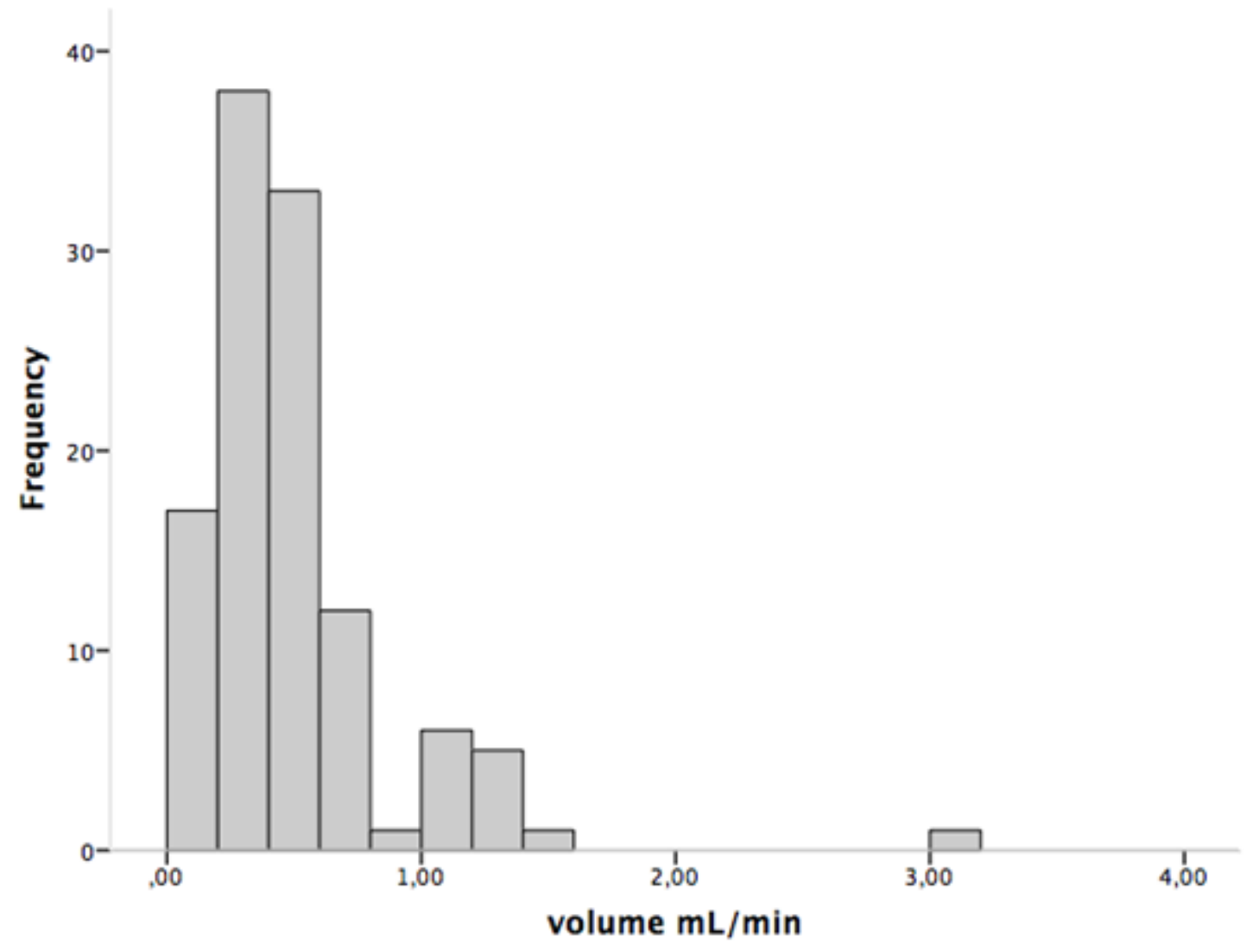

Figure 2

Distribution of stimulated salivary flow volume

\section{Supplementary Files}

This is a list of supplementary files associated with this preprint. Click to download.

- STROBEchecklistcrosssectional.pdf 